\title{
Paideusis
}

\section{Siegel's Transcendental Quest: An Examination of Rationality Redeemed?}

\section{Walter Okshevsky}

Volume 11, Number 2, 1998

URI: https://id.erudit.org/iderudit/1073102ar

DOI: https://doi.org/10.7202/1073102ar

See table of contents

Publisher(s)

Canadian Philosophy of Education Society

ISSN

0838-4517 (print)

1916-0348 (digital)

Explore this journal

Cite this article

Okshevsky, W. (1998). Siegel's Transcendental Quest: An Examination of

Rationality Redeemed? Paideusis, 11(2), 13-25.

https://doi.org/10.7202/1073102ar

This document is protected by copyright law. Use of the services of Erudit (including reproduction) is subject to its terms and conditions, which can be viewed online.

https://apropos.erudit.org/en/users/policy-on-use/ 


\title{
Siegel's Transcendental Quest: An Examination of Rationality Redeemed?
}

\author{
Walter Okshevsky, Memorial University
}

[A] philosopher is never concerned with a condition of things but only with a manner of explanation, and of recognizing that the only thing that matters in a philosophical argument is its coherence, its intelligibility, its power to illuminate, and its fertility.

\section{Introduction}

Michael Oakeshott

Over the past eight years since the publication of his Educating Reason, Harvey Siegel has been subjected to intense scrutiny and a good deal of criticism by philosophers and theorists of education. While never rancorous, and often appreciative of his talents and contributions, a few of his critics have not been particularly kind. Some of this attention is attributable to the academic and professional stature Siegel has deservedly attained: if you are a philosopher or theorist of education, there are not too many issues you can address without eventually having to take some stand on one or more of Siegel's published arguments. Most critics have inveighed against some aspect of his attempt to defend the philosophical coherence and educational implications of the proposition that "the fostering of rationality and critical thinking is the central aim, and the overriding ideal, of education." As was to be expected in these very postmodern times, the presence in this thesis of at least three currently deemed "essentially-contested concepts" opened the methods, claims, and assumptions of Siegel's position to a wide variety of objections, most of which came replete with their own agendas and justifying frameworks. Critiques of Educating Reason (some of which also targeted arguments in Siegel's Relativism Refuted) came from the camps of anti-foundationalism, feminism, narrativism, multiculturalism contextualism, and other forms of postmodernism. Most demanded answers to the questions: Whose rationality? Which version of critical thinking? Education for what? Which version of philosophical analysis? The most philosophically trenchant criticisms focused directly on the core of Siegel's positions-his epistemological theory of rationality -and sought to lay bare its limitations for a variety of problems and issues of contemporary importance within the theory and practice of education.

Rationality Redeemed? is testimony to the seriousness and care with which Siegel has listened to the voices of postmodernism in educational thought. This book-a collection of twelve papers, some with minor editing, others more thoroughly revised-gathers together Siegel's recent published efforts to defend and articulate further both his theory of rationality, and its consequent conception of critical thinking as "a universal educational ideal" against what Siegel terms " 'anti-Enlightenment' currents in philosophy of education and in general philosophy" (1). Despite having too many footnotes, the collection serves as a very convenient, readable, informative, and thought-provoking pursuit of many of the issues and problems raised by the Modernist versus Postmodernist debates in the field of education. Some parts are more technical and offer the advanced 
reader much to reflect upon. All display Siegel's characteristic regard for clarity, logical rigor, and fairness in treatment of interlocutors and critics. They provide a fine opportunity to view a seasoned craftsperson in dialectical conversation with some very prominent thinkers in education.

In my estimation, after being tried in the fire and engaging in sincere dialogue with his critics, Siegel issues from the tests essentially unrepentant and unbowed. He repeats his central thesis from Educating Reason on page 2 of this text and risks perdition itself in formulating many of his replies to his critics in the shape of a specific "meta-narrative": an "Enlightenment-Modernist" that champions the universality, autonomy, neutrality, and objective imperatives of reason. Each essay may profitably be read as a partial answer to the constellating question asked by Siegel in the opening pages of the book: "How, in these postmodern times, can one seriously propose the fostering of rationality-an Enlightenment notion if ever there was one-as a universal educational ideal?" (7). That, in my view, is the question for us today-not only in education but across disciplines and the diverse fields of professional practice. Herein rests much of the significance of his book.

I want to focus on Siegel's theory of rationality not only because there is, indeed, "a close conceptual connection between rationality and critical thinking as an educational ideal" (74) but also for its value in revealing more comprehensively the precise character and direction of Siegel's underlying understanding of the nature, aims, methods, and limits of philosophical analysis, and its value for educational thought and practice. My aim is to show that the account he develops comprises an important articulation and defence of the view that rationality is misunderstood when comprehended as a descriptive term of empirical psychology or sociology but must, rather, be recognized as possessing the irreducibly normative function of a regulative ideal governing the operation of principles and criteria of reason assessment. This focus will not allow me to deal in any detail with particular objections made by Siegel's critics. But I believe what is primarily needed at this point is a clearer recognition of the kind of project Siegel is engaged in and through which he understands his own efforts. Whether Siegel will agree with all aspects of my rendition of his claims, methods and intentions, of course, remains an open question.

\section{The Aim}

On some versions of the received view of Siegel's theory, his old-time Enlightenment meta-narrative appears naively suspended in a time long past and best ignored. At best, it commits the following transgressions. It defends an absolutist Enlightenment conception of rationality innocent of the growing multicultural character of contemporary Western liberal democracies; it undervalues democracy; it is philosophically and politically unprepared to cope with the character and consequences of the fragmentation of our moral and cultural universes; it is marked by the hubris of a view of philosophical analysis which misunderstands its own intrinsic powers and limitations as well as its necessary dependencies upon other forms of discourse; it fails to recognize its own authentic character and value as a contribution to the philosophical analysis of the educational matters and problems it raises and addresses; it strives unrealistically for an epistemology of ultimate justification insisting on searching for answers to some of the most recalcitrant of philosophical questions instead of 
engaging the more practically useful task of offering tentative practical guidelines for the concrete pursuit of knowledge; and it casts rationality in an intellectualized, otiose form devoid of genuine appreciation for the concrete particularities of the realities and problems of human conduct and community solidarity. At times, I have thought that his critics portray Siegel's theory in terms strongly reminiscent of the view of the geometers which Plato has Socrates express in the observation that

their science is in direct contradiction with the language employed in it by its adepts .... Their language is most ludicrous, though they cannot help it, for they speak as if they were doing something and as if all their words were directed toward action ... whereas in fact the real object of the entire study is pure knowledge. ${ }^{1}$

On this received view, Siegel's self-acknowledged "theoretical understanding of rationality" is pictured as a metaphysical and foundationalist anachronistic quest for "the knowledge of that which always is and not of something which at one time comes into being and passes away."

Such strident interpretations of Siegel's work, like most received views, may have polemical value for a short bout of intellectual forensics but offer little by way of an accurate understanding and assessment of Siegel's analysis of rationality and its functions within his over-all philosophical and educational projects. In fact, Siegel's objectives and methods in these essays have more in common with Socrates and Habermas than with Platonic philosophy or other "metaphysico-foundationalist"' accounts. The starting-point for both, I find, is what Habermas refers to as the "unavoidable experience of modernity": the "collision between universes of discourses that has left past conceptions of the unity of reason fragmented and pluralized." 3 Therapy for restoration or reintegration, it is recognized by all parties, can no longer take any a priori or foundationalist form. Our hope is rather to be placed in the pursuit of "theories of rationality that are supposed to account for why and in what sense we can still connect our convictions and descriptive, normative, and evaluative statements with a transcending validity claim that goes beyond merely local contexts." 4 While Siegel definitely shows greater insouciance towards the empirical and reconstructive sciences than Habermas would ever advise, they share a vision of a coherent version of transcendence able to redeem conceptions of rationality, truth, objectivity, and morality which have fallen prey to various forms of sectarianism and balkanization-forms symptomatic of the contemporary fear of intellectual authority and comforting recourse to the alleged sovereignty of discrete "language-games," "frames-of-reference," "discourse-communities," "para- digms of inquiry," "borders of legitimate authority," and even "rationalities." Siegel's quest is inspired in part by a refusal to fall into the trap of arguments to the effect that the nature of rationality, or being reasonable, "entails certain kinds of interactions with other reasonable persons, who we know are themselves reasonable because they are the products of reasonable social circumstances, circumstances we know to be reasonable because they are causally efficacious in producing reasonable persons." This comprises a very neat and tidy argument-characteristics displayed by all spherical shapes. But the circle here is not particularly enlightening or virtuous since it only omits consideration of the theoretical issue at hand. What one can appreciate about 
Siegel's dialogical efforts, despite disagreements on particular claims and arguments, is that he requires more from our capacities for rationality and sensibility and possesses the courage to argue-in a not overly-receptive contemporary educational environment-that a distinctively philosophical form of reflection and inquiry can help to break us out of such cavernous enclosures of the mind.

In appraising Siegel's work, it is good to be clear on the actual questions being raised and pursued. Repeatedly, he is led to parry his critics' thrusts by drawing attention to the difference between philosophical and non- or extraphilosophical questions and modes of inquiry (204). For Siegel, there is such a thing as "a purely philosophical point of view" (103) and it possesses a certain autonomy (68) from empirical research into particular spatio-temporal slices of the world. On my reading, Siegel's central aim is specifically philosophical: he intends "to establish univocal analyses of rationality and of the educational ideal of critical thinking" (7). His analyses of rationality contribute to the philosophical question of what rationality itself is and what it requires. The object of analysis is "the nature of reasons" $(32,117)$ and "the dictates of rationality" (13). His sole aim is "the discovery of philosophical truths" (187) and he sees his account accordingly as primarily a theoretical one: specifically, an epistemological theory understood as "the general theory of knowledge, truth, reasons, justification, and evidence" (16).

However, I read his account of rationality as having not only theoretical but also practical import: an account of what rationality is or means and what its criteria and principles require is simultaneously a prescriptive account of how to proceed rationally. It, thus, sets practical requirements for how and what we are to believe and do. Hermeneutics, as Gadamer writes, "has to do with a theoretical attitude toward the practice of interpretation ..." -but he also sees that "heightened theoretic awareness about the experience of understanding and the practice of understanding, like philosophical hermeneutics and one's own selfunderstanding, are inseparable." The account moves in the direction of what MacIntyre, after completing After Virtue, refers to as "an account of what rationality is"- - specifically, an account which attempts to say "what makes it rational to act [and think] in one way rather than another."6 While Maclntyre's methods and conclusions differ from Siegel's in some important respects, both posit as the explicit object of analysis the conditions of the rationality of thought and action. Siegel, like MacIntyre and Socrates, is concerned with providing an account of the conditions by virtue of which an act or belief is rational, where such an account is not equivocal with what may be taken or deemed to be "rational at some given time and/or by some given community." Siegel's method to achieve "philosophical truth needs to be recognized as tailored to this theoretical/analytic effort to identify the conditions of rationality comprehended as constitutive of its own nature and dictates." What is this method?

\section{The Method}

Siegel's method may be read as a transcendental one. Given the Kantian connotations of this term, however, an important caveat is in order. Siegel makes no attempt to deduce conceptual categories or modes of intuition a priori to experience in the manner of Kant's critical philosophy. The transcendental methodology actually deployed comprises a minimalist version of Kant's ar- 
chitectonic efforts. The investigation into the nature and dictates of rationality takes the form of "establishing that something .... is necessary, in order for something else ... to be possible" (219). The distinctively philosophical character of the project is signalled by the term "possible." Siegel does not write "actual." The force of many of his replies to critics on the epistemological, moral and political issues dealt with in these essays rides on the claim that, while an identification of conditions and factors which bring about the actuality of a phenomenon comprises an empirical inquiry into causal or functional origins, the conditions sought within transcendental inquiry are logical or conceptual conditions which make rationality what it is. Such conditions are necessary for the possibility of some $X$; as such, they are said to be constitutive of, or presupposed by, $X$. In the empirical realm, the relation of cause to the $X$ it brings about is contingent and external; in the transcendental space of philosophical inquiry, the relation of a constitutive condition to the possibility of $X$ is internal and logically necessary.

It follows that the philosophical problem of identifying the nature and dictates of rationality via a reconstruction of its internal logically/conceptually presupposed conditions of possibility cannot be decided by an empirical appeal to what a given individual or community claims to count as rational belief, action, justification, and so on. (As Siegel points out, the very intelligibility of a causal claim presupposes a logically prior conceptual identification of the independent causally-related factors.) Thus, characteristically Siegel argues, for example, not that a concern for the justification of $P$ is necessary in order for the valuing of $P$ to be possible, but rather that the concern for justification is necessary for the "justified, serious valuing of ... [P]" (219). What makes valuing possible, what conditions its possibility, is what makes the valuing of $P$ what it genuinely is, and these constitutive features have no necessary relation to what may at any given time be, in fact, thought to be such features. It is what philosophical conceptualizations and analyses of a thing or act, $P$, individuate as "P." It is also what identifies and gives sense to such analyses: $P$ in its "justified sense," or as Siegel also writes, in its "appropriate" or "genuine sense."

It is in virtue of this methodological concern with the nature or possibility of rationality as a philosophical matter, rather than with its perception or actuality as an empirical one, that Siegel argues that "putative criteria of reasonassessment" are not necessarily "appropriate criteria of reason-assessment" (32), that "perceived justification is of no necessary relevance to "the nature and conditions of genuine justification" (127), that what actually moves a person or community to hold a belief or value or engage in some practice may be different from "being appropriately moved by reasons" (2) and that a claim which "serves as a reason within some community may be incorrectly identified as "being a good reason" (124). When specifying expressions such as "justified," "serious," "appropriate," or "genuine" are not explicit, the transcendental space of analysis is signalled by the modal term "must": "The critical thinker must have some knowledge ... ; must be the master of . . ; must actually engage in ... ; must habitually seek ..." (3).

There is nothing contradictory in acknowledging that rationality from this transcendental point of view necessarily presupposes the possibility of error as a necessary condition of itself. Fallibilism is an intrinsic condition of rationality, 
including transcendental rationality. That is, there must (as a necessary logical condition) be the possibility that what is "putative"/"claimed" may not be "genuine"/"true." Without such a possibility for error (corrigibility), "correctness" or "justifiability" would itself be rendered impossible. To claim otherwise-to claim, for example, that the nature of rationality is "to be identified with normatively sanctioned practices found within discourse communities"-is, on Siegel's project, not a very propitious beginning for a philosophical theory of rationality since such an identification reduces epistemic warrant to essentially non-epistemic factors such as culture, psychology, or the current procedures and methods of specific disciplines and, thus, undermines the very possibility for rationality as an epistemological object of analysis. Such an identification entails that "there is no role for criteria to play in assessing specific activities, descriptions and judgments as rational or not" (105). ${ }^{7}$ The identification denies what we can refer to as the condition of "criterial autonomy-a logically necessary condition constitutive of the nature of rationality, and a kind of condition the search for which identifies the distinctiveness and autonomy of Siegel's transcendental philosophical investigations.

Criterial autonomy refers to that possibility for error ("fallibilism"), and, hence, correctness or justification, which reason-giving necessarily presupposes and which the reduction of epistemic/philosophical warrant to non-epistemic warrant illegitimately denies. Reasons, on Siegel's account, function to provide "probative weight" or "warranting force" for the truth of a conclusion or the commendation of a course of action and their normative "goodness" or "success" in performing this function is a mark of their justifiability. It is as such that justifiability itself functions as a criterion of reason-assessment (15) enabling the assessment of the "justificatory status of an argument" (207). An argument must always be open to assessment of the appropriateness, relevance, and legitimacy of the criteria employed and applied within the act of reasongiving: "Any particular judgment must admit of criterion-based evaluation, however fallible-including judgments of the adequacy of such criteria themselves. Any view which denies this fails as a view of rational or reasonable judgment" $(110,125)$. What follows at this point is an account of what criteria of reason-assessment themselves necessarily entail. This is a matter which exercises a number of critics and is at the heart of many current debates on the nature of rationality.

\section{Criteria, Principles, Contexts}

In Educating Reason and in these essays, Siegel maintains that no judgment or argument can accept "arbitrariness, inconsistency, and partiality." The possibility for genuine reason-giving is conditioned, in part, by the deployment of criteria of reason assessment by means of which the 'genuine' justifiability of an argument, the "warranting force" of its reasons, can be established. Siegel also retains from Educating Reason the logical consequence that the principles necessarily presupposed in applying criteria of reasonassessment require "a recognition of the binding force of standards [criteria], taken to be universal and objective, in accordance with which judgments are to be made." This is a transcendental claim about the principles that criteria of reason assessment must abide by in order to function genuinely as criteria. 
As a transcendental claim, it asserts a logical condition about how judgments "are to be made given the nature and dictates of rationality." It does not refer to the obvious empirical facts that what counts or is recognized as a legitimate criterion or principle within a tradition of inquiry or culture is subject to change and that cultures and traditions differ. It refers, rather, to a necessary condition of the possibility of genuine reason-giving and its assessment: the condition that "the principles which determine the compellingness [justifiability] of reasons at a time apply to all putative reasons impartially and universally."10

On this transcendental view, certain conceptions regarding truth and rational justification "are necessary ingredients of any proposed justification" (146). The impartiality, universality, and objectivity of criteria and principles of reason-assessment comprise epistemic ingredients which are "person-and culture-neutral . . . apply[ing] with equal force to all persons and cultures (144). We must be careful in interpreting this claim since it is doubly open to misinterpretation. On the one hand, as already seen, it may be mistaken for a patently false empirical claim. On the other, we may misunderstand the transcendental significance of a constitutive condition of reason-assessment: the condition of "context-specificity" as it applies to the objectivity, universality, and neutrality/impartiality of criteria of reason-assessment. Such context-specificity, as I understand it, is central to the principle of fallibilism and to the "absolutism" of Siegel's theory.

Siegel is usually quite careful in delineating the specific context he is speaking about in discussing the kind of criteria that genuine reasons presuppose (are necessarily required to abide by) and with reference to which assessment is made possible. (The identification of context is typically a minimal one in that relevant criteria may also function appropriately in other contexts.) The following are examples. In the context of particular issues in education, "the justification of educational principles and policies must necessarily rest on neutral principles" (145). In the case of our practices and justifications of teaching for critical thinking, "we must think there are criteria, binding upon all reasoners, in accordance with which the strengths of reasons and arguments are appropriately determined" (20). In the liberal justification of multicultural educational initiatives, argument "presupposes a particular view of justification, according to which particular descriptions, principles, and claims admit of nonculturally bound justification.... [This view] must be accepted, on pain of incoherence or inability to justify such initiatives" (147). And in deciding whether democratically-orchestrated social change is a sufficient criterion for justifiable social change: "[ $t]$ here are independent criteria-concerning fairness, nonoppression, equality, justice, etc. - which social changes must meet in order to be rightly regarded as good or desirable ..." "(96-97). In these examples, the principles of objectivity, neutrality, and universality governing the possibility of genuine justification and legitimate criteria of reason assessment are identified in their applicability to a specific issue or set of issues making up some identifiable discursive context. Principles and criteria comprise ingredients of argument-analysis and rationality which Siegel argues must be recognized to comprise necessary ingredients of any proposed justification.

However, as I read it, necessity and universality do not apply directly to criteria themselves, for which specific criteria are able to meet these principles 
in any given case or context of reasoning vary with the content of the argument under consideration and with context-specific methodological features of a discourse or scheme. Jurisprudential and political criteria that govern permissible amendments to the Canadian Constitution, for example, both differ from each other and from criteria governing the aesthetic qualities of a work of art or the formal validity of a deductive argument. On Siegel's transcendental analysis, we cannot specify a priori one final and absolute set of objective, universal, and neutral criteria of reason-assessment applicable to all cases of justification across all possible semantic and discursive contexts. This would comprise what could be called a "vulgar absolutism" of criteria of reason assessment which Siegel would abjure. "[R]ationality," as Rescher writes, "is universal, but it is circumstantially universal." 11

But neither would Siegel accept the view, held by Toulmin, for example, that justifiability is totally an "intra-field, not an inter-field notion" such that "the merits to be demanded of an argument in one field will be found to be totally absent (in the nature of things) from entirely meritorious arguments in another." 12 Such a view on Siegel's account is beguiling because it conflates criteria of reason assessment, which do and must vary across discursive contexts and communities, with principles of reason assessment which do not and cannot. ${ }^{13}$ The view fails to recognize the necessarily dual character of reason as, to use Putnam's words, "both immanent (not to be found outside of concrete language-games and institutions) and transcendent (a regulative ideal that we use to criticize the conduct of all activities and institutions.)" 14

At times, Siegel does leave himself open to a misreading of the senses of "absolutism" and "universality" here by not always drawing clearly the distinction between principles of reason assessment and criteria of reason assessment required to meet the conditions identified by the principles. Confusion is easy since principles are themselves criteria of reason-assessment at a higher order of abstraction; they function as second-order criteria or meta-criteria. Moreover, both principles and criteria function as "standards-a term Siegel typically uses to refer to both meta-criteria/principles and first-order criteria. He writes, for example, that "the goodness-the power and probative force-of reasons is universally applicable: if $p$ is a good reason for $q$, then anyone who is justified in believing that $p$, and who believes that $q$ on the basis of $p$, is equally justified in believing that $q(149)$ or that "[t]heorizing is governed by fallible but universally applicable standards" (171). These claims can easily be misread and misinterpreted as applying directly to criteria of reason assessment and can be read as a requirement for an absolute, universal, and contextually independent establishment of first-order criteria. But they do not so require, and they cannot so require, and Siegel does not think that they do or can.

Such claims refer directly to principles (i.e., objectivity, universality, neutrality, etc.) and only indirectly to criteria. Whatever the first-order criteria of reason assessment turn out to be within some context or discourse, their selection and application must meet higher principles of universality, objectivity, impartiality, and so on. But matters pertaining to the legitimacy of particular criteria are always relative to context: "the rationality of particular judgments ... . is relative to context" (105). This, too, must be carefully read for rationality is not something determined by context (105); the justificatory status of an argument-which includes the legitimacy of operative criteria of reason 
assessment-depends upon their accordance with independent, trans-contextual principles of reason assessment. To deny that the principles of rationality are universally applicable ingredients of any justifiable argument-to claim that principles are not absolute but do vary across contexts and communities, such that these contexts and communities determine or constitute what rationality itself means-would be to undermine the grounds upon which we claim (as we must) that our judgments and our appraisals of the epistemic worth of judgments are not "arbitrary, inconsistent, or partial." If we do not see the need to avoid such a claim and maintain that our judgments may well be "arbitrary, inconsistent, or partial," then we have no grounds for maintaining any claim, including that one. A stance requires a ground. And that form of scepticism is viciously self-defeating.

Principles will not be respected in the same way by criteria. ${ }^{15}$ Different contexts, different issues and different kinds of claims require different kinds of evidence and reasoning. Such variation affects the selection and legitimacy of criteria deployed. Consequently, different kinds of discourses must proceed in methodologically different ways given the particular subject-matter of inquiry. This epistemological point is the basis of one of Siegel's major and abiding educational recommendations:

[A] person learns the proper assessment of reasons by being initiated into the
traditions in which reasons play a role. Education, on this view, amounts to
the initiation of the student into the central human traditions. These
traditions-science, literature, history, the arts, mathematics, and so on-have
evolved, over the long history of their development, guidelines concerning
the role and nature of reasons in their respective domains. ${ }^{16}$ At times, Siegel's educational recommendations sound more classically "premodern" than "modern" in Wilfred Carr's excellent appropriation of the sense of the former term from Macintyre. For Siegel clearly accepts the role and value of initiation into the disciplines for the development of moral and intellectual virtues in Carr's sense:

For an apprentice to fail to perform in accordance with [disciplinary] standards of excellence was thus not simply a failure to display certain specified competencies and skills. It was a failure to transform himself from a person whose power of reason was governed by natural inclination and untutored taste, into a person whose intelligence and reason were directed, disciplined and educated in accordance with moral and intellectual virtues. ${ }^{17}$

In one of the most crucial passages of the book for understanding Siegel's epistemological theory of rationality, he writes:

We judge community-based and contextual claims, evaluations and practices, and we strive to do so fairly. In so doing, we strive to judge in accordance with criteria that are neutral with respect to the issue being considered. But those criteria, while neutral in the sense just specified, are not neutral with respect to all controversies or contexts. (127)

This is a major reason, for Siegel, why philosophy or epistemology cannot function as a "foundational" discipline or "grounding" for all or any other disciplines or "communities of discourse." At times, Siegel invites postmodem attacks in saying such foundationalist-sounding things as that his epistemological account "underwrites," "underpins," "underlies," the theoretical under- 
standing of criteria and principles of reason assessment ( $34 \& 35$ ) when he actually means only that we can make no coherent sense of rationality and its educational ideal of critical thinking independently of his substantive epistemological theory.

Such a theory, of course, is itself required to abide by the identified principles of rationality and, rather than underwriting these principles, is itself underwritten by those same principles. In epistemological theory, as in any discourse, "the goodness of reasons will depend in part on the theoretical and methodological situation within the relevant discipline" (117). However, from a purely philosophical point of view, it is because the possibility for genuine judgment and argument presupposes not only context-specific criteria but these as established in accordance with the principles of objectivity, universality and neutrality that Siegel is able to say: "A field may be a partial arbiter of the goodness of reasons within its domain, but it is not and cannot be the sole arbiter"' (33).

\section{Conclusion}

Philosophy-specifically epistemology-retains a certain autonomous status as tribunal: its jurisdiction covers matters to do with whether and how criteria of reason-assessment either meet or do not meet universally applicable principles of rationality. Again, this claim regarding the principled legitimacy of criteria is transcendental, not empirical: a given consensus or lack of consensus on principles is never decisive in justifying the selection of criteria of reason assessment or claims that specific reasons do or do not meet the criteria given. Epistemology comprises "a theoretical understanding of the nature of reasons according to which putative criteria are recognizable as appropriate criteria of reason assessment"' (32). The term here is "recognizable," not "recognized," highlighting Siegel's consistent concern with conditions of possibility. It is in virtue of the irreducibility of the epistemic status of principles and criteria of reason-assessment to non-epistemic status that Siegel writes: “Epistemology's task is not to decide what in fact is a good reason in history, physics, or indeed any particular disciplinary [or cultural] context ..." (117).

Siegel specifies the task of epistemology within this transcendental project in the following way:

to theorize about the nature of reasons, and their goodness, such that a good reason in one context bears the same relation to that for which it is a reason as a good reason in another context bears to that for which it is a reason.

This view of the theoretical task of epistemological analysis remains essentially unchanged from its formulation in Relativism Refuted:

Such a theory must include an account of reasons, such that it is possible to establish that, independent of framework, scheme, or other relativizing factor, there is a relation $R$ between claims $p$ and $q$ such that the claim ' $p$ is a (good) reason for $\mathrm{q}^{\prime}$ is (absolutely) true. ${ }^{18}$

That trans-contextual inferential relation holds absolutely and remains the same kind of requirement across all possible cases of good reasons. In other words, whether $p$ is a good or justifiable reason for $q$ requires an analysis of whether (or to what extent) the criteria of reason assessment deployed within the 
argument are legitimate and are met, and such an analysis must itself accord with the principles of reason assessment. Siegel's transcendental project seeks to develop "univocal analyses": the philosophical truth about the nature of this sameness of inferential relation and the character of its dictates for rational belief and action across differing contexts. The quest for this nature defines the distinctiveness and autonomy of philosophical (epistemological) analysis and theory.

Of course, all self-conscious argument critically examines reasons and the relevance and legitimacy of the criteria deployed and does so in accordance with the above principles. But what remains distinctive and autonomous about epistemology transcendentally conceived is that it posits as its object of analysis the conditions constitutive of (necessary for) the genuine nature or possibility of good reasons. It seeks what it is that makes or determines rationality what it is: what rationality is, what 'rationality' means, rationality itself (105). Only thus can epistemology genuinely seek the means to distinguish putative criteria from appropriate criteria of reason assessment.

What we can now see is that it is only in virtue of the trans-contextual and self-identical sameness of inferential relation " $R$ " that we are able to speak of "universality," "objectivity," and so on as principles of rational justification. Only by presupposing the sameness of " $R$ " as the self-identical nature of inference are we able to make judgements which, while necessarily originating and embedded within some particular discursive context or scheme, can yet be claimed to retain a certain scheme-independence "in the sense of having legitimacy and point beyond the bounds of the scheme in which ... [judgment] is embedded" (216). The presupposition of the sameness of the inferential relation " $R$ " across particular contextualized schemes (and across their respectively different criteria of reason assessment) thus functions as a measure or meta-standard for gauging the justifiability of judgment. It is, as I understand it, precisely the accordance with such a measure which Siegel's principles of reason assessment ultimately require for rationality in its own genuine nature. In other words, rationality is here thought in the form of the correctness of judgment.

\section{Mohanty writes:}

The transcendental point of view cannot be achieved all at once, at one shot, as it were from a pistol, to use Heidegger's words; but, like liberty, it needs constant vigilance. It is an on-going affair of philosophical self-criticism. ${ }^{19}$

What the self-identical and trans-contextual sameness of the inferential relation " $R$ " looks like at the end of transcendental inquiry can only be glimpsed by us at present through our particular and fallible struggles to provide reasons for what we say and do, and our attempts to appraise their justifiability via (contextspecific) criteria of reason assessment in accordance with principles of objectivity, universality, and impartiality. The philosophical quest for the transcendental unity of reason amidst its differentiation and fragmentation can only be pursued through the kind of relentless philosophical self-criticism of which Mohanty writes.

It is, in my mind, simply irrelevant to argue that such transcendental analysis has little pragmatic pay-off in concrete and particular cases of rational deliberation. It can be argued, for example, that in the real world principles, 
criteria, and reason assessment reveal their genuine character within deliberation upon such problems as how a proportionate assessment of the ethical status of a university-based research project can justifiably be attained in light of a conflict between the principle of respect for persons and the principle of justice as fairness in the distribution of benefits and burdens to research participants. Or, whether political expediency gained at the price of human rights is worth the cost in a particular case. But an entrancement with the particularities of the given case and the specificity of varying contexts of deliberation easily risks precisely that arbitrariness, partiality, and consensus for the sake of parochial forms of solidarity which constitutes a denial of what may well be universal and necessary obligations of impersonal reason.

At this point, we are not in a position to pronounce final judgment on this transcendental matter without begging all the important questions. Those that glimpse it, quest after it. And Harvey Siegel's work, in my estimation, provides an exemplar of the kind of persistence, vigilance, and self-criticism a philosophical project requires. As educators, we owe Siegel's new book a read-especially so in these very postmodern times.

\section{Acknowledgment}

I am deeply indebted to Michael J.B. Jackson for his meticulous reading of this paper and his many suggestions for improvement. I am also grateful to Terry Piper for her careful reading and helpful comments on an earlier draft.

\section{Notes}

1 Plato, The Republic in The collected dialogues of Plato edited by Edith Hamilton and Huntington Cairns (Princeton, NJ: University Press, 1980), 527a.

2 Ibid., $527 \mathrm{~b}$.

3 Jurgen Habermas, "Questions and counterquestions," in Habermas and modernity edited with introduction by Richard J. Bernstein (Cambridge, MA: MIT Press, 1985), 193.

4 Ibid.

5 Hans Georg Gadamer, "Hermeneutics as practical philosophy," in After philosophy: End or transformation? edited by Kenneth Baynes, James Bohman, and Thomas McCarthy (Cambridge, MA: \& London, England: The MIT Press, 1987), 337-8.

6 Aladair Macintyre, Whose justice? Which rationality? (Notre Dame, IN: University of Notre Dame Press, 1988), ix.

7 The transcendental claim that the possibility for coherent functioning of criteria comprises a necessary condition of rationality is also at work in Siegel's rejection of designating truth qua correspondence to an independent reality as a criterion of judgment: there is no possible way for us to establish when (the conditions under which) the criterion is met (207) and that is to say that such a criterion cannot possibly function as a genuine criterion of reason-assessment.

8 Harvey Siegel, Educating reason: Rationality, critical thinking, and education (New York \& London: Routledge, 1988), 34.

${ }^{9}$ Ibid.

10 Ibid, 135. 
11 Nicolas Rescher, Objectivity: The obligations of impersonal reason (Notre Dame and London: University of Notre Dame Press, 1997), 12.

12 Stephen Toulmin, The uses of argument (Cambridge: Cambridge University Press, 1969), 255.

13 Despite significant differences in their final accounts such as the one noted, there remains significant overlap between Siegel's theory and Toulmin's account of argument analysis as developed in The Uses of Argument, op. cit., 11-43, 94-106. $1982,8$.

14 Hilary Putnam, "Why reasons can't be naturalized," Synthese, 52,

15 I owe this formulation to Michael J.B. Jackson.

${ }^{16}$ Harvey Siegel, Educating Reason, op. cit., 59.

${ }^{17}$ Harvey Siegel, "Professing education in a postmodern age, Journal of Philosophy of Education, 31(2), 1997, 320.

18 Harvey Siegel, Relativism refuted: A critique of contemporary epistemological relativism (Boston: Reidel Publishing, 1987), 169.

19. J.N. Mohanty, "Transcendental philosophy and the hermeneutic critique of consciousness," in Hermeneutics: Questions and prospects, edited by Gary Shapiro and Alan Sica (Amherst, MA: The University of Massachusetts Press, 1984), 120. 